\title{
The Evolution of Liver Injury Diagnosis and Treatment in the Past 50 Years
}

\author{
Charles E Lucas
}

\section{ABSTRACT}

Background: During the past 50 years many changes have occurred in treating liver injury. Nonoperative therapy (NOT) for blunt penetrating injuries is now common.

Study design: This report highlights the current therapy of liver injury.

Results: Complications of NOT include early rebleeding requiring prompt operative intervention; intrahepatic hematoma which becomes infected necessitating drainage; bile peritoneum requiring exploration and drainage; and hemobilia requiring embolization, hepatotomy with ligation, or resection. Operative exposure through a midline incision which can be extended as a median sternotomy is preferred. Prehepatic and intrahepatic packs are helpful. Full mobilization of the right and left triangular ligaments augments exposure. Hemostasis for both blunt and penetrating, usually, is obtained by hepatorrhaphy using the 2' blunt tipped needle swedged onto a 2-O chromic suture. Through-and-through injuries may require hepatotomy with intrahepatic ligation of cross-linking vessels. Locally destructive wounds may require nonanatomic debridement to the point of healthy liver tissue which is then sutured. Formal segmentectomy, or lobectomy, is seldom needed. Hepatic artery ligation controls deep arterial not involving the portal venous supply. The retrohepatic caval atrial shunt will facilitate hemostasis from central liver injuries involving the hepatic veins or retrohepatic cava.

Debridement of emacerated liver tissue should be extended to good liver parenchyma where deep liver sutures help with approximate the edges.

Drainage is not used for minor injuries. Closed suctions are best for larger wounds. Common duct drainage should be avoided.

Conclusion: Most liver injuries are treated by NOT. Operative therapy involves hemostasis, debridement when necessary, and selective drainage.

Keywords: Liver, Hepatic injuries, Nonoperative treatment of solid organ injury, Solid organ injury, Hepatic injury complications.

How to cite this article: Lucas CE. The Evolution of Liver Injury Diagnosis and Treatment in the Past 50 Years. Panam J Trauma Crit Care Emerg Surg 2014;3(3):124-131.

Past President of PTS and Professor

Department of Surgery, Wayne State University, Detroit Michigan, USA

Corresponding Author: Charles E Lucas, Past-President and Professor, Department of Surgery, Wayne State University Detroit Michigan, USA, e-mail: clucas@med.wayne.edu

\section{Source of support: Nil}

Conflict of interest: None

\section{RESUMEN}

Antecedentes: Durante los últimos 50 años se han producido muchos cambios en el tratamiento de lesiones hepáticas. La terapia no quirúrgica (NOT) para lesiones penetrantes y contundentes es ahora muy común.

Método de Estudio: Este reporte señala la terapia actual de lesiones hepáticas.

Resultados: Las complicaciones de la NOT incluyen el re-sangrado precoz que requiere intervención quirúrgica inmediata; hematoma intra-hepático el cual se infecta necesitando de drenaje; peritonitis biliar que exige una exploración y drenaje; y hemobilia requiriendo de embolización, hepatotomía con ligadura o resección. La exposición operativa a través de una incisión en línea media, que puede extenderse a una esternotomía media es preferida. Empaquetamiento pre-hepático e intra-hepático son útiles. Movilización completa de los ligamentos triangulares derecho e izquierdo aumenta la exposición. La hemostasia tanto para lesiones cerradas o penetrantes, por lo general, se obtiene por hepatorrafia usando la aguja de punta embotada de 2 pulgadas con una sutura crómica 2-O. Heridas que pasan de un lado al otro pueden requerir hepatotomía con la ligadura de los vasos intra-hepáticos. Heridas destructivas locales pueden requerir desbridamiento no anatómico hasta el punto de tejido sano del hígado, luego de lo cual es suturado. La segmentectomía formal o lobectomía , rara vez son necesitadas. Ligaduras de arteria hepática arterial controla sangrado arterial profundo sin implicar el suministro de la vena porta. La derivación arterial-cava retro-hepática facilitará la hemostasia de lesiones hepáticas centrales que involucran las venas hepáticas o cava retro-hepática. Desbridamiento de tejido hepático macerado debería extenderse a parénquima hepático sano donde las suturas hepáticas profundas ayudan con la aproximación de los bordes.

El drenaje no se utiliza para lesiones menores. Succiones cerradas son mejores para las heridas más grandes. Drenaje del conducto común debe ser evitado.

Conclusión: La mayoría de las lesiones hepáticas son tratadas por NOT. La terapia Operativa implica hemostasia, desbridamiento si es necesario, y el drenaje selectivo.

Palabras clave: Hígado, Lesiones hepáticas, El tratamiento no quirúrgico de lesiones de órganos sólidos, Lesiones de órganos sólidos, Las complicaciones de lesiones hepáticas.

\section{INTRODUCTION}

The liver is the largest and most frequently injured organ in the body. This is true for both penetrating wounds and 
blunt injury. ${ }^{1}$ During the past 50 years, there have been remarkable changes in the approach to liver injury. ${ }^{2,3}$ During the 1960s, the diagnosis of blunt liver injury was made primarily by repeated physical examination looking for peritoneal tenderness in association with unexplained instability. Since all abdominal penetrating wounds were explored, the diagnosis of incidental liver injury was made early. Consequently, there were many negative laparotomies or nontherapeutic laparotomies in patients with either blunt or penetrating liver injuries. ${ }^{4}$

During the 1970s, the incidence of nontherapeutic laparotomies decreased. The introduction of diagnostic peritoneal lavage (DPL) in the assessment of blunt abdominal trauma showed that an effluent of less than $100,000 \mathrm{RBC} / \mathrm{ml}$ precluded the need for laparotomy searching for a source of intraperitoneal bleeding. Many nontherapeutic laparotomies, however, were performed for patients with red cell counts greater than 100,000 RBC/ml.1 Concomitantly, the practice of local exploration of stab wounds eliminated negative laparotomy for nonpenetrating wounds. Many nontherapeutic laparotomies, however, continued to be performed.

The routine use of computed tomography provided an opportunity to make an early diagnosis of liver injury, initially, after blunt trauma but later after penetrating trauma. ${ }^{1,5}$ Unfortunately, the identification of any liver injury during this era led to routine laparotomy so that the incidence of nontherapeutic laparotomy actually increased. Nonoperative therapy (NOT) of intraabdominal solid organ injuries had not yet arrived.

\section{SELECTIVE NONOPERATIVE THERAPY}

The first study identifying a selective NOT approach to patients with splenic injury began in $1978 .{ }^{6}$ The early

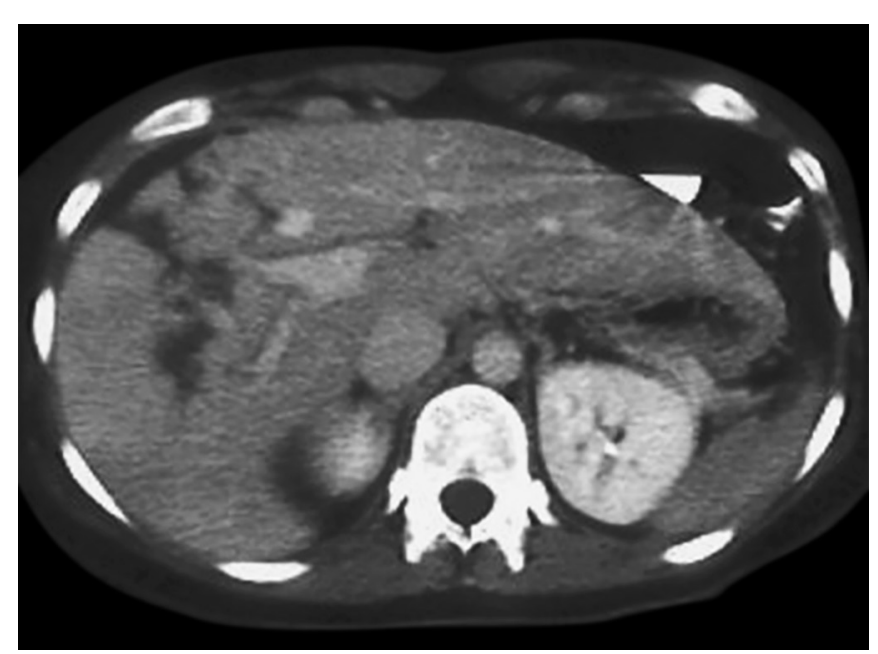

Fig. 1: This 27-year-old woman sustained a type 4 liver injury in a head on motor vehicle collision in 1983. She underwent NOT as her hemoglobin fell to $8.9 \mathrm{gm} / \mathrm{dl}$; she was not transfused. She went home on postinjury day 5 success with nonoperative therapy for splenic injury led to the same approach for patients with known liver injury usually identified by CT scan. ${ }^{1,7}$ The author has been using the NOT approach to liver injury since 1981 (Fig. 1). More confidence with this approach, based upon early successes, led to a policy, whereby, a stable patient with a positive DPL (more than 100,000 ml) and a verified liver injury seen on CT scan, would be treated expectantly. Although there are many reports suggesting that NOT of known liver or splenic injury should be based upon the abbreviated injury score with the minor (I-III) injuries being relegated to NOT and the major (IV-V) injuries being exploration, all of these injuries should, initially, be considered for NOT. ${ }^{8.9}$ There are few minor injuries which cause instability and need to be explored. Likewise, there are some major injuries that can receive NOT. ${ }^{1,9}$ Successful NOT requires that the patient remains stable and does not require RBC transfusion to maintain vital signs. This judgment becomes more complex when the patient has bleeding of nonhepatic origin, especially, a pelvic fracture. The current policy for patients to be continued on NOT allows the hemoglobin to fall below $10 \mathrm{gm} / \mathrm{dl}$. When the patient who has a hemoglobin which falls to less than $10 \mathrm{gm} / \mathrm{dl}$ and, in addition, requires blood transfusion for hepatic bleeding to maintain vital sings, immediate operative or angiographic intervention is indicated. ${ }^{1}$ When patients receive NOT for blunt liver injury, they should be aggressively ambulated whenever the pain thought to be related to the liver injury abates and they should be started on diet when bowel function returns. ${ }^{1}$ They seldom require SICU monitoring and there is no need for repeat CT scans since the decision is based upon clinical findings and not serial images. The successful use of NOT for blunt liver injury has extended to the treatment of penetrating wounds from either stab wounds or low-velocity gunshot wounds. This is particularly true when patients have a right upper quadrant or lower thoracic stab or gunshot wound which causes a hemothorax requiring tube thoracostomy but is not associated with peritoneal tenderness typically seen with hollow viscus injury. ${ }^{5,7}$ When the abdominal CT scan demonstrates no evidence of hollow viscus injury and the patient is stable, the NOT approach is likely to be successful. The institution of ambulation and restoration of diet should follow the same principles as seen following blunt liver injury. The application of NOT for the treatment of both blunt and penetrating liver injuries led to a marked decrease in nontherapeutic laparotomies.

\section{COMPLICATIONS OF NONOPERATIVE THERAPY}

Despite the tremendous success that has been achieved with NOT of liver injury, there are a number of complica- 


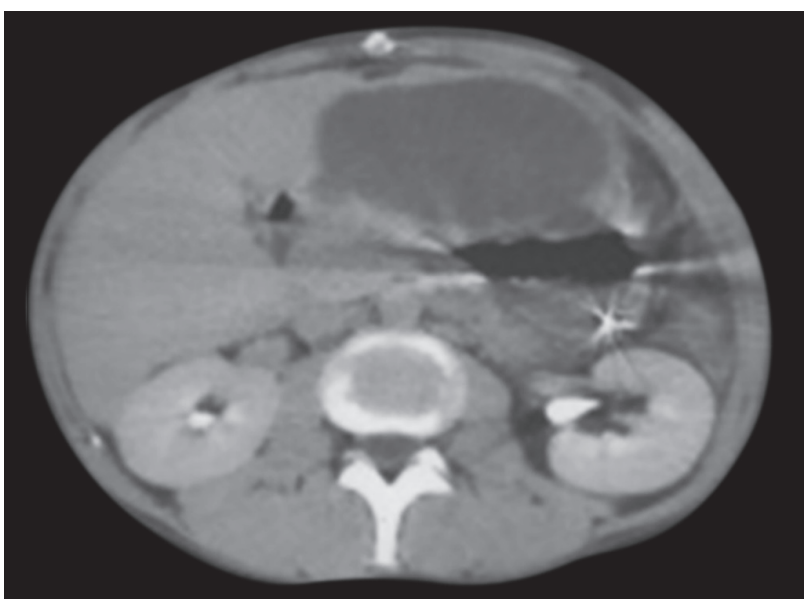

Fig. 2: This 45-year-old man was successfully treated for a grade 3 liver injury but returned to the hospital 3 weeks later with a left lobe liver abscess at the site of injury. The hematoma likely became seeded with bacteria as a result of contaminated intravenous heroin injections

tions. The first and most feared complication is rebleeding which usually occurs within the first 24 hours but may occur as long as a week following injury. ${ }^{1,10}$ These patients should be taken directly to the operating room when the first unit of blood is being administered for delayed hemorrhage. The hemostatic techniques which can be used to control this bleeding are discussed later.

Patients who are discharged home after successful NOT often have an intrahepatic hematoma (Fig. 2). This usually resolves but on occasion becomes seeded with bacteria resulting in an hepatic abscess. This is more likely to occur in patients who are using illicit street drugs, particularly, 'mixed jive' which is a diluted heroin preparation. ${ }^{1}$ The patient will present with fever, pain, and leukocytosis. The intrahepatic abscess can usually be drained percutaneously but if there is evidence of the abscess having ruptured, laparotomy with irrigation plus drainage is indicated.

Occasionally, patients with a major liver injury being successfully treated nonoperatively will develop the picture of severe 'ileus' with distention, pain, and tenderness. ${ }^{1}$ Imaging will demonstrate a large fluid collection within the peritoneal cavity which, when aspirated, is bilious. Such patients require laparotomy with evacuation of the bile which may exceed three liters. Following evacuation, generous drainage near, but not in, the liver injury is essential. Attempts to treat the injury which is not bleeding should be avoided as the bile leakage will subside. ${ }^{1}$ These patients seldom have concomitant hemorrhage. The patient will be markedly improved the day after operation and, if the bile leakage is still present at the time of discharge, it will gradually decrease over the next month. There is no need to perform t-tube choledochostomy or endoscopic bile duct stenting

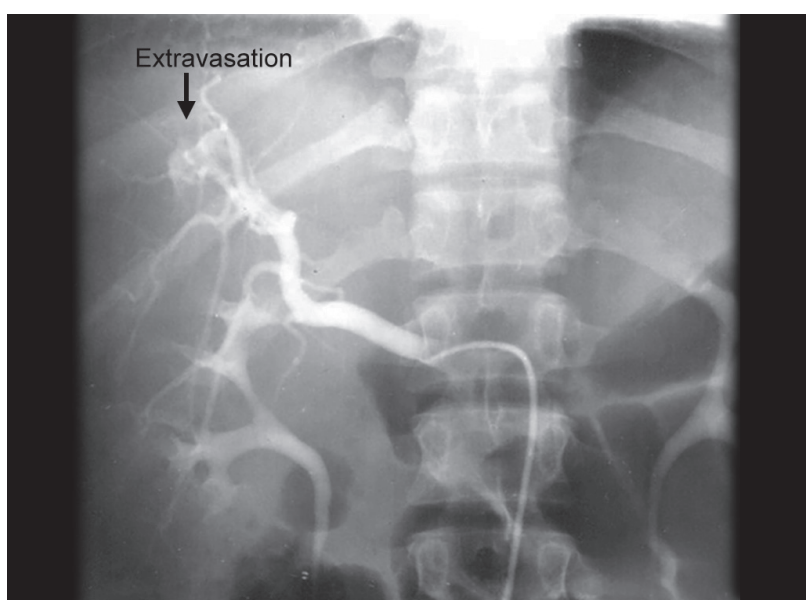

Fig. 3: One week following blunt abdominal injury from a car/tree collision, this young man presented to the hospital with right upper quadrant pain followed by hematemesis and relief of the pain. This classic triad for hemobilia should stimulate hepatic arteriography which will likely demonstrate a false aneurysm as seen here

in these patients since these bile fistulae routinely close unless there is an extrahepatic bile duct injury. ${ }^{11,12}$

Another complication of NOT for major liver injury is an intrahepatic hematoma which communicates with both a partially severed intrahepatic artery and an adjacent partially severed intrahepatic bile duct. ${ }^{1,13}$ This leads to hemobilia which can be suspected on the basis of the triad of late postinjury abdominal pain, followed by hematemesis, and relief of the abdominal pain. ${ }^{13}$ The hematemesis is caused by the rapid decompression of the hematoma through the bile ducts into the duodenum leading to the reflexive vomiting of blood. The patient should undergo hepatic arteriography rather than upper endoscopy (Fig. 3).

\section{LIVER MOBILIZATION}

Once exposed during laparotomy, deep injuries require mobilization of the liver in order to achieve hemostasis. The left lobe can be mobilized by dividing the falciform ligament and the left triangular ligament to the level of the vena cava. As the vena cava is approached, the left hepatic vein will be seen over a distance of about $1 \mathrm{~cm}$ as it passes from the medial aspect of the left lobe to the anterior left lateral portion of the cava (Fig. 4).

Mobilizing the right lobe requires that the right triangular be taken down completely along with the bare area of the liver (Fig. 5). This allows the liver to be mobilized anteriorly and medially being careful to avoid injury to the right adrenal veins. ${ }^{1,710}$ As the mobilization is extended toward the inferior vena cava, the short hepatic veins will be identified coursing from the caudate lobe to the anterior wall of the vena cava; these small veins have to be controlled very carefully. Even though these veins 


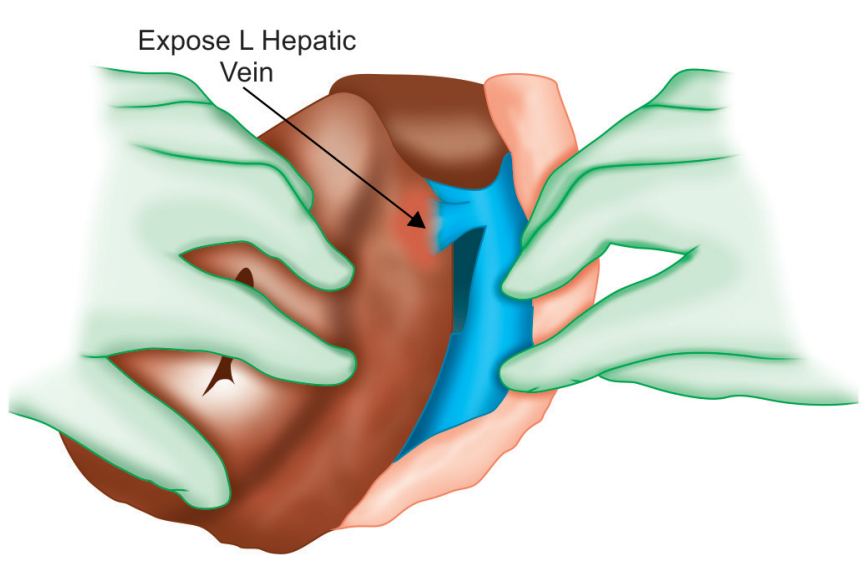

Fig. 4: Division of the left triangular ligament followed by anterior mobilization of the left lobe allows one to see the left hepatic vein entering into the inferior vena cava

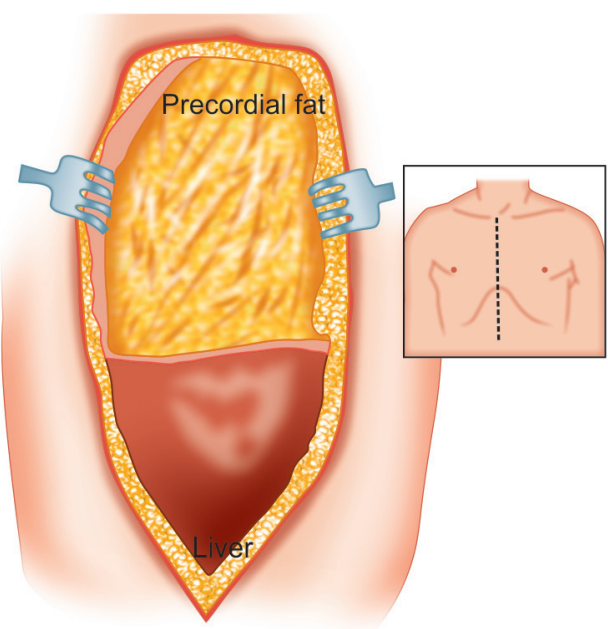

Fig. 6: When patients require laparotomy for liver injury, an upper midline incision is preferred; this can be extended up into the chest through a median sternotomy if both proximal and distal vena caval control are needed

are small in size, they cause significant bleeding which interferes with the field of view.

The superior surface of the liver is best mobilized by way of the median sternotomy and division of the diaphragm in the median plane down to the diaphragmatic hiatus. This exposes the suprahepatic cava just above the entrances of the left hepatic vein and the right hepatic vein. ${ }^{1,10}$ When accessing the mid-plane of the liver between the right and left lobes through the gallbladder bed, the mid-hepatic vein will be identified passing straight anterior from the inferior vena cava where it bifurcates into the right and left branches. Anticipation of the bifurcation of the mid-hepatic vein as it courses from the cava to the liver will help prevent entering into that vein before the bifurcation.

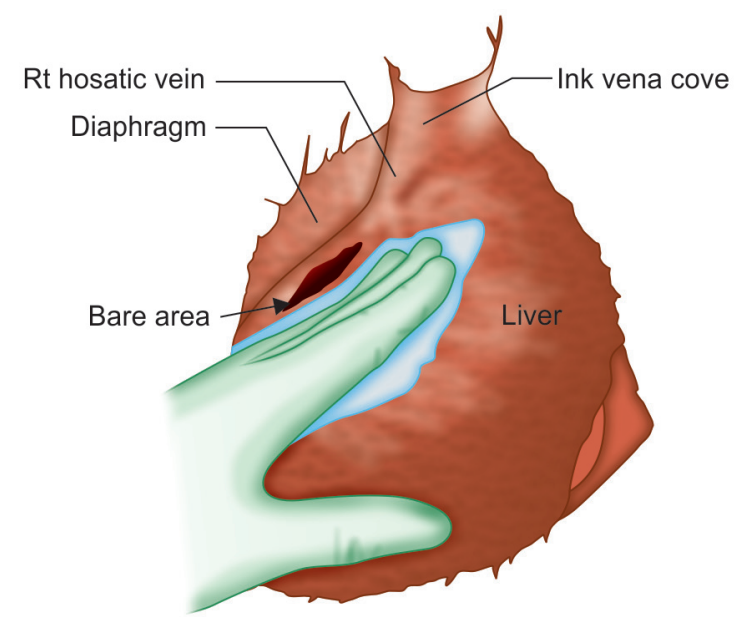

Fig. 5: When dividing the right triangular ligament in order to mobilize the right lobe, the bare area on the diaphragm must be taken down carefully to avoid injury to the diaphragm

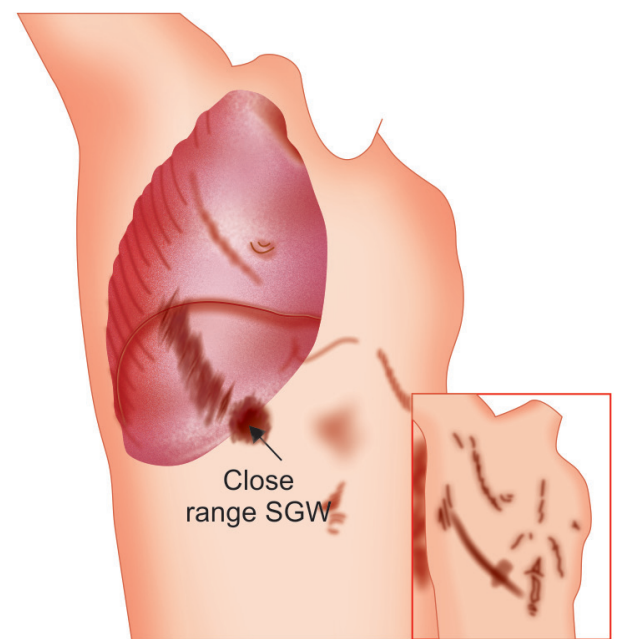

Fig. 7: Rifle wounds or close-range shotgun blasts to the right upper quadrant and right lower chest are best approached through an oblique incision through the defect; this will provide excellent exposure to all of the right lobe of the liver, right lower lobe of the lung, and other intraabdominal viscera

\section{OPERATIVE CONTROL OF LIVER BLEEDING}

When a patient with liver injury requires laparotomy for hemostasis, the midline incision is usually the most appropriate since it allows for extension inferiorly to the pubis and superiorly up into the chest through a median sternotomy (Fig. 6). ${ }^{1,7}$ If the bleeding site is on the posterior right side of the right dome of the liver, the extension of the upper midline incision can be made into the right chest as a right thoracoabdominal incision. Occasionally when the injury is due to a rifle wound or close-range shotgun blast which is clearly involving only the right lateral lobe, an oblique incision can be made extending along the right eight rib, continuing down into the abdomen with extension to the midline; dividing 


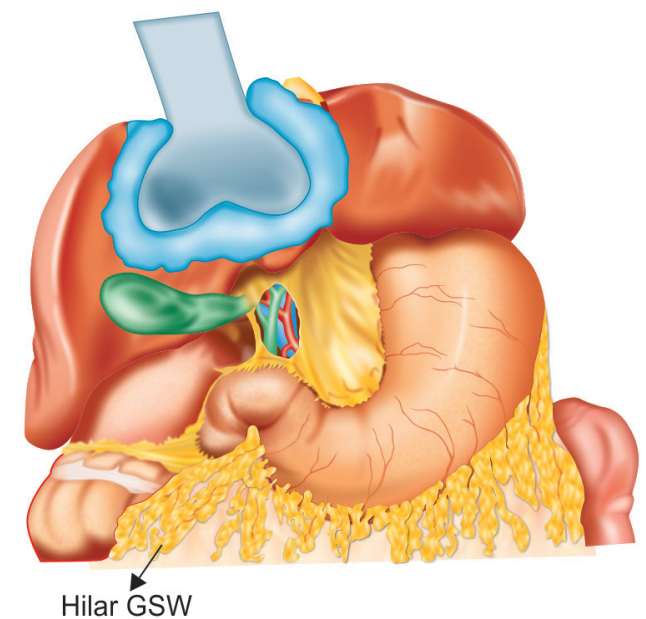

Fig. 8: Penetrating wounds near the hilum can be temporarily controlled by gauze packs supported by a retractor; the packs, ideally, are placed inferiorly and superiorly on the liver

the diaphragm gives excellent thoracic and abdominal exposure (Fig. 7). All injuries in the right lateral lobe can be completely accessed, thus, facilitating successful treatment. Likewise, stab wounds which are confined to the right upper quadrant or low velocity gunshot wounds in the upper quadrant, often in association with a nonlifethreatening hemothorax, can be approached through a right subcostal incision which, on rare occasions, may be extended superiorly in the midline by doing an xiphoidectomy or, in very rare occasions, by teeing off the right subcostal incision into the right chest. ${ }^{1,710}$ When the latter teeing off of a right subcostal incision into the right chest is necessary, the original decision to make the right subcostal incision was poor judgment. Often patients undergoing emergency operation for bleeding from liver injury, are no longer bleeding during laparotomy. Alternatively, when patients have continued bleeding, rapid placement of abdominal lap packs over the liver injury while assessing for any other intraabdominal injuries will often be rewarded by the fact that the temporary pack control has caused the actively bleeding injury to become hemostatic (Fig. 8). ${ }^{1,14,15}$ The surgeon should affirm that the patient is stable and is receiving no vasoactive drugs to artificially maintain the blood pressure. The packs should be removed and the abdomen closed. Based on the treatment of over 300 patients no longer bleeding when the abdomen is opened or after pack removal, one can be confident that no hemostatic technique should be applied. There has been many examples, however, where well-meaning efforts to suture nonbleeding liver injuries have led to significant bleeding requiring aggressive technical hemostasis and the need to give multiple blood transfusions. ${ }^{1,14}$ The old principle of 'Let the sleeping dog lie' applies to the nonbleeding liver injury in a stable patient.

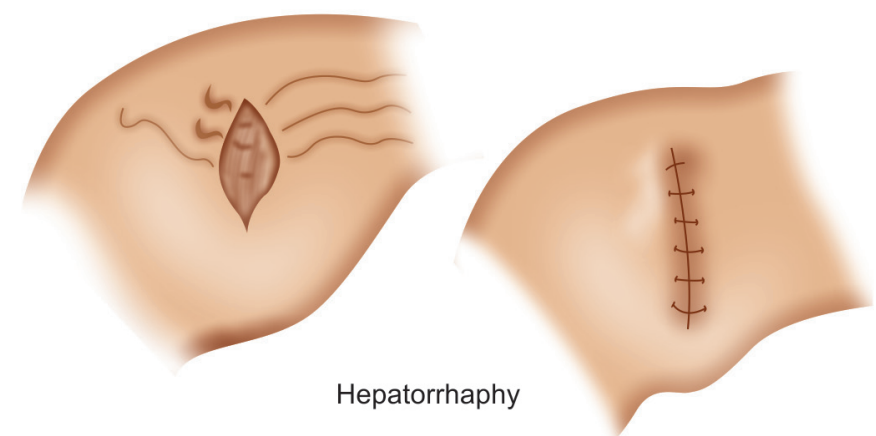

Fig. 9: The placement of large liver sutures with a 2' blunt tipped needle swedged onto a 2-O chromic suture provides successful hemostasis for most liver injuries

When the liver is actively bleeding, the injury should be compressed with packs which are held in place either digitally or by a Balfour retractor while attention is directed elsewhere to make sure there are no other critical injuries. ${ }^{1,14}$ Once the packs have been in place for 15 minutes and there is no evidence of oozing, as would be judged by the welling up of blood around the packs, the packs should be carefully removed, ideally, in the order that they were placed and in a very gentle manner in order not to stir up rebleeding. As mentioned above, this often is the only hemostatic technique that is needed and the patient can be closed. During the period of time when the packs are in place, the anesthesiologist should optimize the patient's condition knowing that the packs are soon to be removed. ${ }^{1,15}$ When the pack is gently removed and there is recurrent bleeding, then one needs to apply one of the hemostatic techniques.

\section{HEMOSTATIC TECHNIQUES}

The optimal hemostatic technique varies with the site and type of active bleeding. The most frequent successful type of hemostasis is placement of liver sutures using the $2^{\prime}$ blunt tipped needle swedged onto a 2-O chromic suture (Fig. 9). ${ }^{1,710}$ The blunt tip allows for the surgeon to place the needle deep into the liver with the dominant hand while feeling for the blunt tip coming through the liver with the nondominant hand without fear of injury to the finger. Most of the stab wounds, gunshot wounds, and linear blunt tears of the liver are actively bleeding from multiple small vessels within $2-3 \mathrm{~cm}$ of the liver capsule. The liver suture permits the compression of these areas. When the first liver suture is placed, it should be held by the assistant while a second liver suture is placed. The first liver suture is then tied while the assistant brings the second liver suture together so that the liver is com- 


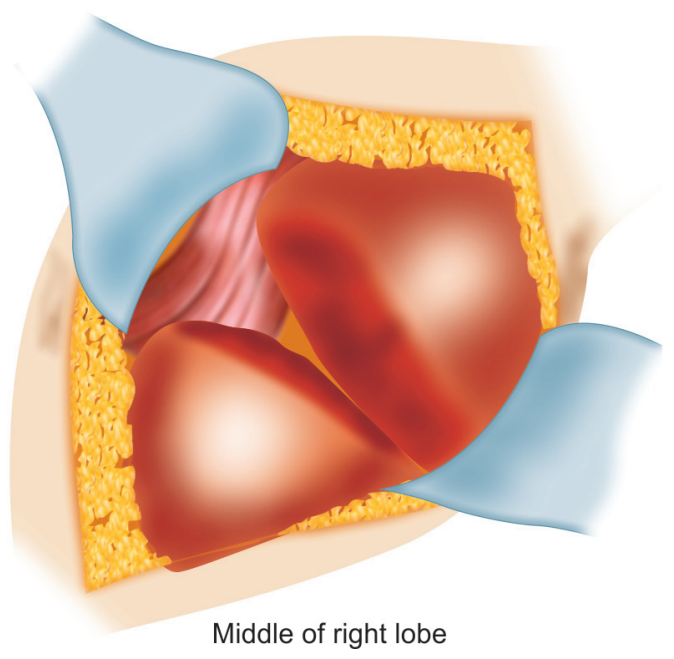

Fig. 10: Tractotomy from the entrance to the exit of a throughand-through gunshot wound allows the crosslinking vessels to be identified and ligated after which the liver can be reapproximated with the liver sutures

pressed but not torn or made ischemic. Careful placement and tying of the liver sutures in this manner prevents the problems with liver necrosis with subsequent intrahepatic abscess within the area of necrotic parenchyma.

One of the taboos in the treatment of the bleeding liver is the teaching that one should never close both the entrance and the exit site of a through-and-through gunshot wound. ${ }^{1}$ Actually, suture closing of both the entrance ad exit site with deep liver sutures has been successful in controlling bleeding from through-and-through gunshot wounds on many occasions. After the sutures have been placed, the surgeon should observe both the entrance and the exit site since; if there is any continued bleeding from the deeper crosslinking vessels, this blood will make it to the entrance or exit site (usually the most dependent site) within the next ten minutes. This identifies the fact that this injury is not amenable to closing both the entrance and the exit site and one has to resort to one of the other hemostatic techniques.

\section{HEPATOTOMY}

When a through-and-through gunshot wound continues to bleed after suture closure of the entrance and exit sites, the patient is a candidate to have the sutures removed and a hepatotomy performed by filleting the liver open down to the missile track (Fig. 10). ${ }^{1,710}$ Although the author has typically used the finger fracture technique, the use of the long GIA staple may be helpful to more rapidly expose the track and identify the crosslinking vessels which can sequentially be controlled, clamped, divided, and ligated. When the finger fracture technique is used, the crosslinking vessels are best controlled by ties or suture ligation rather than staples because during the exposure of the track, the Ray-Tec sponges tend to catch onto the

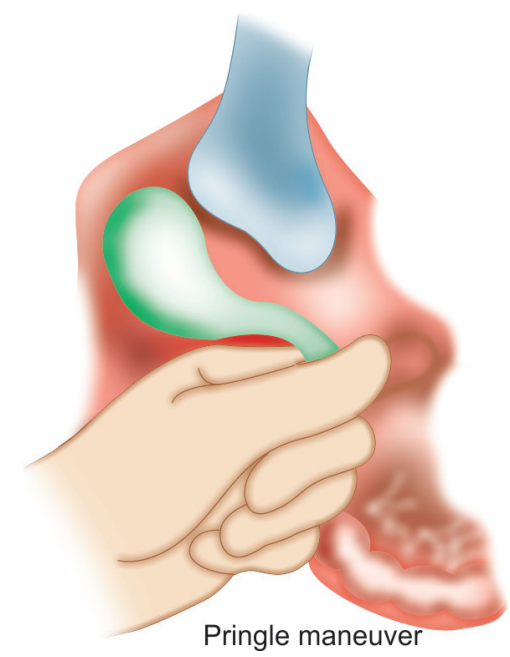

Fig. 11: The Pringle maneuver allows the surgeon to get temporary hemostasis due to active bleeding from a branch of the hepatic artery or portal vein

staples and, when removed, cause the staples to avulse the adjacent crosslinking vessels.

\section{THE STELLATE EXPLOSIVE RIGHT LOBE INJURY}

Some patients with severe deceleration injury have a socalled explosion of the mid-right lobe and, when seen at the time of laparotomy, will exhibit deep stellate cracks which clearly go down into the depth of the liver. ${ }^{1,7,14}$ Temporary control can be obtained by small gauzes within the cavity plus pack control superior and inferior to the liver while the patient is being stabilized, recognizing that liver sutures are not going to work for this type of wound. One adjunct in the control of deep bleeding is the Pringle maneuver whereby the left index finger is placed in the foramen Winslow between the major and lesser sacs, while the left thumb is brought down on the left index finger to get control of the porta hepatis (Fig. 11)..${ }^{79}$ When the Pringle maneuver stops active arterial bleeding from a large intrahepatic tear, one can carefully free up the hepatic artery so that only the hepatic artery is occluded with a noncrushing clamp. ${ }^{1,13}$ When this causes cessation of bleeding, the clamp can be left on for 15 minutes and then removed. If minor recurrent bleeding ensues, it can often be controlled with hepatorrhaphy using the liver sutures. When the recurrent bleeding is major, then the clamp must be reapplied and the hepatic artery dissected distally to try to get the branch of the hepatic artery which is the source of bleeding. With large right lobe injuries, this will usually be the right hepatic artery which is then ligated; the gallbladder should be removed as the cystic artery often arises distal to the site of the ligation. Such patients require resection of the ischemic liver. Since the liver receives most of its 


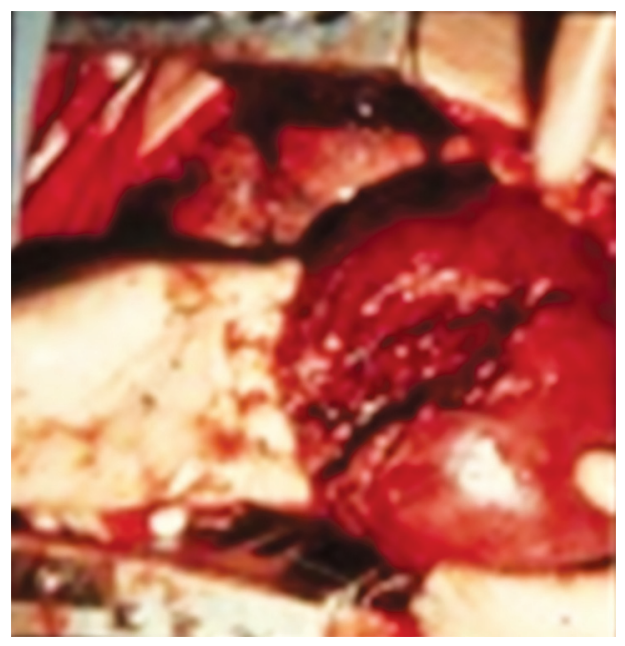

Fig. 12: A large macerating injury to the midportion of the right lobe from a high-velocity rifle wound is treated by anatomic resection. One surgeon digitally compresses the medial aspect of the right lobe which has been fully mobilized, while the second surgeon completes the anatomic resection

oxygenation by way of the portal vein, selective dearterialization will typically be associated with hepatic survival in the absence of portal venous injury to that same segment. ${ }^{15,16}$ When the patient has an associated right portal venous injury, ligation of the right hepatic artery will lead to liver necrosis. ${ }^{16}$ When a patient sustains a low velocity gunshot wound which enters the liver, passes through into the lumen of the cava, and embolizes into the heart or pulmonary artery, the patient often does not have bleeding since the path of least resistance for blood is into the communication between the liver and the cava. ${ }^{1}$ When no bleeding is identified in this circumstance, the best thing to do is to put in a drain, treat other injuries, and leave the known communication between the liver and cava alone. When there is obvious bleeding, this area is packed while appropriate personnel are mobilized in order to put in a retrohepatic shunt (caval-atrial) and do a direct repair on the caval injury and potential hepatic venous injury. ${ }^{14}$

\section{HEPATIC RESECTION}

Although popular at one time, hepatic resection can usually be avoided as a hemostatic technique for liver injury. ${ }^{17,18}$ There are different types of resection. Patients with close-range shotgun blasts or high-velocity rifle injuries will often have maceration of a segment of the injury. ${ }^{1,5,7}$ These patients are candidates for wedge nonanatomic resections which may actually remove more than $25 \%$ of the liver substance but without necessitating dissection of the major hepatic veins or the porta hepatis. Again, the author prefers the finger fracture technique with individual ligation of the crosslinking vessels with the resection done through normal liver; the GIA stapler has also been used to facilitate wedge resection.

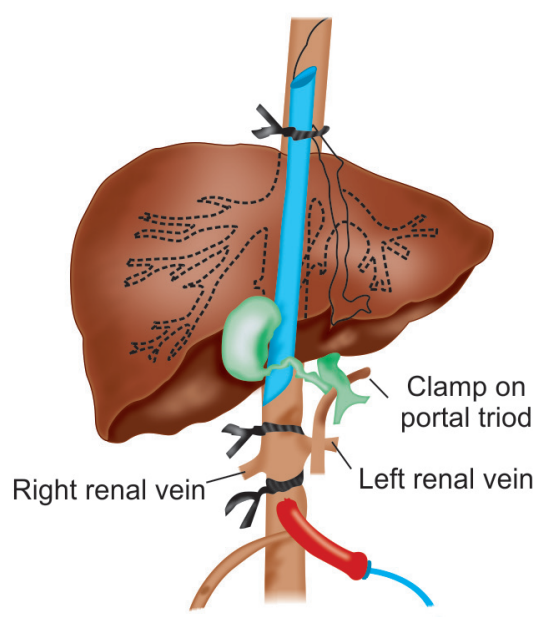

Fig. 13: In patients with devastating liver injuries around the inferior vena cava or the hepatic veins can have liver isolation by a retroperitoneal vena cava atrial shunt

\section{ANATOMIC HEPATECTOMY}

The most challenging technique for hemostasis is an anatomic hepatectomy. ${ }^{19,20}$ This is reasonably straightforward and simple when it involves only the left lateral segment which is quite easily and rapidly removed after mobilizing the left triangular ligament and dividing the falciform ligament. Formal right hepatic lobectomy requires more difficult approaches following full mobilization of the right triangular ligament and the bare area of the liver. For right hepatic lobectomy, the liver needs to be delivered into the wound by an anterior and medial rotation while the first assistant places his hands around the medial aspect of the right lobe to function as a tourniquet. The surgeon can then dissect off the injured lateral portion (Fig. 12). Knowledge of the vascular and ductal anatomy and experience with hepatic resection facilitate right hepatectomy for a severely injured liver. ${ }^{20}$ Having the availability of a liver surgeon when this type of procedure in indicated is most helpful.

When the injury is deep enough to involve the major hepatic veins, a retrohepatic caval-atrial shunt may be indicated (Fig. 13). This is best achieved by extending the midline incision as a median sternotomy followed by dividing the diaphragm in the median plane to the esophageal hiatus so that one has access to the right atrium, the suprahepatic cava, and the infrahepatic cava. There are no lumbar veins superior to the renal veins thus eliminating bleeding from lumbar veins during this procedure. The short gastric veins, however, which connect the quadrate lobe of the liver to the anterior wall of the vena cava require careful ligation. Again, during the actual resection, the author prefers the finger fracture technique but other techniques such as the stapling devices may be helpful. 


\section{DEBRIDEMENT}

The second principle of providing care to the injured liver is debridement. This is seldom needed in patients with stab wounds, low velocity gunshot wounds, or in patients with linear tears after deceleration injury. ${ }^{1,7}$ Most debridement is needed in patients with emacerated parenchyma that is seen with high-velocity rifle wounds and close range shotgun blasts. These injuries create ragged parenchyma with the extent of parenchymal damage being so bad that the placement of liver sutures fails because there is no perch of healthy liver to hold the sutures. Using the techniques described above, the emaciated segments can usually be excised about $1 \mathrm{~cm}$ beyond the point of injury in order to get to normal parenchymal where the crosslinking vessels can be appropriately ligated after which the parenchyma is brought together with the liver sutures. As indicated above, sometimes it requires segmentectomy or resection of major portions of the liver.

\section{DRAINAGE}

Whereas drainage was once uniformly recommended for liver injuries, it is now realized that patients with minor injuries that require operative intervention do no need drainage if, indeed, there is excellent hemostasis. ${ }^{1}$ Patients with through-and-through gunshot wounds that are made hemostatic have the potential for postoperative bleeding so that drains are helpful to identify such bleeding. Furthermore, patients with deep parenchymal injuries are candidates for either postoperative bleeding and/or biliary drainage which is evacuated by drains. The most effective drains for achieving this objective are the large round suction drains (Jackson-Pratt). When a patient requires reoperation for bile peritoneum, the author will use a combination of suction drains and old fashioned rubber Penrose drains with the Penrose drains brought out a stab wound which accommodates two fingers.

\section{REFERENCES}

1. Lucas CE, Ledgerwood AM. 'Treatment of Liver Injuries: An Overview.' In Operative Techniques for Severe Liver Injury Rao Ivatury Ed. Springer 2015;2:9-28.

2. Lucas CE, Ledgerwood AM. Treatment of the injured liver. In: Nyhus LM, Baker RJ, editors. In Mastery of Surgery. 2nd ed. Little, Brown and Co Boston: Toronto, London; 1992. p. 850.

3. Feliciano DV, Mattox KL, Jordan GL, et al. Management of 1000 consecutive cases of hepatic trauma (1979-1984). Ann Surg 1986 Oct;204(4):438-445.

4. Lucas CE, Ledgerwood AM. Factors influencing morbidity and mortality after liver injury. Ann Surg. 1978;44:106.

5. Feliciano DV. Surgery for liver trauma. Surg Clin North Am. 1989;69:273.

6. Lucas CE, Ledgerwood AM. Splenic Preservation. In Mastery of Surgery 5th Edition. JE Fischer, KI Bland Eds. Lippincott, Williams and Wilkins 2007;50:1670-1678.

7. Kozar RA, Feliciano DV, Moore EE, et al. Western Trauma Association/Critical decisions in trauma: operative management of blunt hepatic trauma. J Trauma 2011 July;71(1):1-5.

8. Moore EE, Cogbill TH, Jurkovich GJ, et al. Organ injury scaling: spleen and liver (1994 revision). J Trauma 1995 Mar; 38(3):323-324.

9. Trunkey DD. Hepatic trauma: contemporary management. Surg Clin North Am 2004 Apr;84(2):437-450.

10. Pachter HL. Prometheus bound: evolution in the management of hepatic trauma - from myth to reality. J Trauma. 2012;72:321.

11. Lucas CE, Ledgerwood AM. Controlled biliary drainage for large injuries of the liver. Surg Gynecol Obstet 1973 Oct;137(4): 585-589.

12. Lucas CE. Endoscopic retrograde cholangiopancreatography for bile leak after severe liver trauma (letter to the editor). J Trauma Acute Care Surg 2012 Feb;72(2):537.

13. Sandblom P. Hemobilia: biliary tract hemorrhage. Springfield, IL. Thomas 1972.

14. Feliciano DV, Mattox KL, Burch JM, et al. Packing for control of hepatic hemorrhage. J Trauma 1986 Aug;26(8):738-743.

15. Lucas CE, Ledgerwood AM. Perihepatic packing. In. Encyclopedia of Intensive Care Medicine. Vincent JL and Hall JB Eds. Springer-Verlag, Berlin Heidelberg. 2011.

16. Lucas CE, Ledgerwood AM. Liver necrosis following hepatic artery transection due to trauma. Arch Surg 1978 Sep; 113(9):1107.

17. Lucas CE, Ledgerwood AM. Changing times and the treatment of liver injury. Am Surg 2000 Apr;66(4):337-341.

18. Lucas CE, Ledgerwood AM. The academic challenge of teaching psychomotor skills for hemostasis of solid organ injury. J Trauma 2009 Mar;66(3):636-640.

19. Chen RJ, Fang JF, Lin BC, et al. Factors determining operative mortality of Grade V blunt hepatic trauma. J Trauma 2000; 49:886.

20. Polanco P, Leon S, Pineda J, et al. Hepatic resection in the management of complex injury to the liver. J Trauma 2008 Dec;65(6):1264-1269. 